\title{
EDM ASSISTED BY MAGNETIC FIELD FOR ARMOURED STEEL
}

\author{
T. A. El-Taweel ${ }^{1}$, A. R. El-Desouky ${ }^{1}$ and W. M. Farouk ${ }^{2}$ \\ ${ }^{1}$ Mechanical Design and Production Engineering Department \\ Faculty of Engineering, Minoufiya University, Shebin El-Kom, Egypt \\ ${ }^{2}$ Mechanical Engineering Department, Faculty of Engineering, \\ Helwan University, Helwan, Egypt
}

\begin{abstract}
The present paper presents a study on the performance of electrical discharge machining (EDM) assisted by magnetic field for armoured steel (HV500). Response surface methodology (RSM) has been utilized to model, analyze and determine the optimal parameters setting in the EDM process assisted by magnetic field. The process performance criteria such as; material removal rate (MRR), tool wear rate (TWR), were evaluated. Peak current, magnetic flux density, duty factor, and dielectric fluid pressure have been considered the main factors affecting EDM assisted by magnetic field performance. RSM was employed to develop the experimental models. The EDM process assisted by magnetic field process has proved its adequacy to machine armoured steel alloy under acceptable metal removal rate and minimum tool wear rate. The metal removal rate generally increases with the increase of the magnetic flux density and peak current value. The effect of duty factor was limited and dielectric fluid pressure has a moderate effect. Further, the minimum tool wear rate has been obtained at the parametric combination of higher magnetic flux density and higher duty factor when machined by EDM assisted by magnetic field with copper electrodes. It has also been clarified that the effect of magnetic flux density was limited on metal removal rate with graphite electrodes. It has also been found that the minimum tool wear rate was obtained at the parametric combination of higher magnetic flux density, higher peak current and lower duty factor, when machined by EDM assisted by magnetic field, with graphite electrodes.

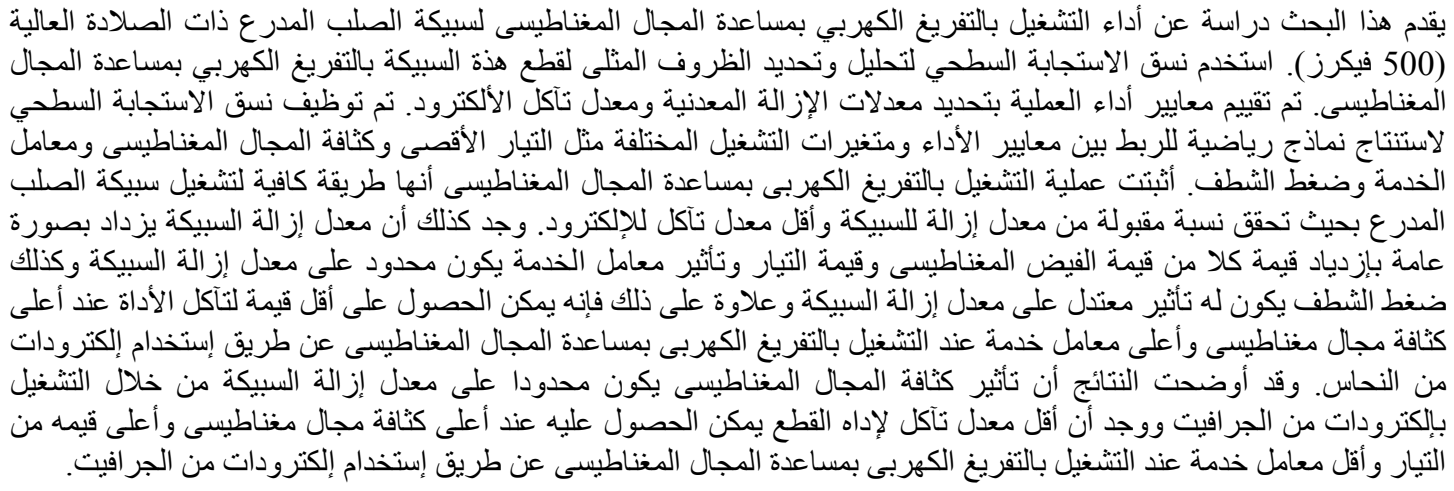

Keywords: EDM, Armoured Steel Alloy, Material Removal Rate (MRR), Tool Wear Rate (TWR), Magnetic Flux Density, Response Surface Methodology (RSM).

\section{INTRODUCTION}

In recent years, there has been an increased interest in advance materials having high hardness, temperature resistance, and high strength to weight ratio and used in mold and die making industries, aerospace components, medical appliance, and automotive industries. In response to this, there is a great demand for new technologies to meet the unique challenges posed while manufacturing components with such materials [1]. The development of appropriate machining systems to support this growth is essential because the traditional processes are unable to cope up with those challenges. Electrical discharge machining 
(EDM) has been a mainstay of manufacturing for more than six decades, providing unique capabilities to machine "difficult -to- machine" electrically conductive materials with desire shape, size, and required dimensional accuracy. It is the most widely and successfully applied machining process for various work piece materials in the field of advance industries [1]. However, its low machining efficiency and poor surface finish restricted its further applications [2].

Material in EDM is removed by melting and vaporization of both the electrodes. A portion of the molten material resolidifies on the electrode itself and the rest of the material forms debris unless removed promptly, this debris may cause un controlled secondary sparking (arcing) which causes a damage to the workpiece surface and reduction in the machining efficiency [3]. Hence, to achieve high aspect ratio of machining, it is critical to have an effective debris removal mechanism. In the EDM process, various sizes of discharge craters would display on the machined surface when the surplus materials were removed and the surface quality of the machined surface will be deteriorated in accordance with the presence of craters. In addition, the machining debris suspended within the dielectric fluid would accumulate in the machining gap to induce the abnormal electrical discharge, so the stability of the EDM progress would be disturbed. Therefore, if the debris in the machining gap can be expelled effectively and completely, the EDM process appears to be a potential candidate to attain high efficiency, high precision, and high quality surface [3]. Many attempts have focused on the applications of using magnetic force to promote the manufacturing technique in recent decade $[1,2]$. However, these investigations only focused on the magnetic abrasive developments and used magnetic abrasive to finish either inner or outer of the machined surfaces. The experimental results reported that the magnetic force process was one of the most promising processes that can be regarded as an attractive and excellent alternative for surface finishing process. Bruijn et al. [4] investigated the effect of magnetic field on the gap cleaning and indicated that the magnetic field can improve gap cleaning. Nevertheless, there are few relative reports associated with the magnetic force used in EDM process to improve the machining characteristics. The ability to expel the machining debris was a crucial factor for maintaining the stability of EDM progress, so the machining efficiency and the quality of surface integrity associated with an EDM process were directly affected by this ability.

Several researchers have investigated the effects of dielectric flush and ejection mechanisms of machining debris for EDM [5-9]. Rajurkar and Pandit [5] proposed a debris ejection mechanism from the analysis of shock waves resulted from electrical discharge. Masuzawa et al. [6] investigated a dynamic jet flushing method, and their experimental results showed that the sweeping jet method was superior to conventional fixed jet flushing. Cetin et al. [9] investigated the effect of electrode jump height on the machining speed of EDM and proposed a debris exclusion model. For improving the expelling of machining debris to prevent the debris clogged in the machining gap. Several researchers carried out their studies by providing ultrasonic vibration through electrodes (either tool electrode or workpiece electrode), as well as dielectric fluid to solve the debris accumulation and to maintain the stability of the machining progress [10-14]. Their research reports revealed that the preventing of the debris, accumulated in the machining gap, had an important benefit on the improving of the machining efficiency.

Furthermore, the added abrasives that acted as an ultrasonic media for the combined process of EDM with ultrasonic machining (USM) can be regarded as the surface strengthening agents transferred to the machined surface through ionization of discharge column during the process [14]. The combined process of EDM with USM had the potential to prevent debris accumulation, to improve machining efficiency, and to modify the machined surface. However, to design an USM equipment for machining large area was intensively constricted, and the degree of tool fastened on USM system was rigorous. Therefore, to construct the combined process of EDM with USM for various workpiece dimensions with convenient, effective and economic features was a complicated work and a real challenge. Especially, when using the EDM process to manufacture a mold with a large projection area.

Response surface methodology (RSM) has been widely used in engineering analysis, and it reveals the potential to solve the setting optimal machining parameters associated with a process with multiple performance characteristics [15-16]. Therefore, the approach of RSM will facilitate the development of a novel process to fit the demands of industrial applications. In this investigation, the effects of EDM essential parameters such as peak current (Ip), magnetic flux density $(\beta)$, duty factor $(D)$ and dielectric fluid pressure $(P)$ were varied to determine their effects on material removal rate (MRR) and tool wear rate (TWR). RSM experimental design method was utilized to plan the experiments in this work. In addition, RSM was employed to develop the experimental models. Analysis of variance test has also been carried out to check the adequacy of the developed models. 


\section{EXPERIMENTAL DETAILS}

\subsection{Experimental Procedure and Measurements}

In this investigation, magnets were attached to the EDM machine to develop an innovative process known as EDM assisted by magnetic field. Using this device, a series of experiments have been conducted to explore the effects of the main machining parameters on MRR, and TWR.

In the present study, MRR, TWR have been considered to evaluate the machining performance. MRR, and TWR are correlated with the input machining parameters such as; peak current (Ip), magnetic flux density $(\beta)$, duty factor (D) and dielectric fluid pressure $(\mathrm{P})$. The experiments were conducted on an AGETRON advance (USA) die-sinking EDM machine. Figures. 1 and 2 show photograph for the test rig and schematically diagram for the action of machining debris driven by magnetic force during the EDM process assisted by magnetic field. Copper and graphite electrodes were used in the EDM process assisted by magnetic field process with dimension of $9 \times 9 \times 28 \mathrm{~mm} 3$. The workpiece material used in these experiments was high performance armoured steel with dimensions of $8 \times 10 \times 16 \mathrm{~mm} 3$. Table 1 shows the chemical composition of the armoured steel. The selection of this material was made, taking into account its wide range of applications in military and automotive industries. It can be classified as a difficultto-cut material, not suitable for traditional machining. During machining, commercial kerosene was circulated as the dielectric fluid with side flushing technique. The machining time for each experiment was variable and related to the machining conditions and fixed parameters which are listed in Table 2. These were chosen through reviews of experience, literature surveys, and some preliminary investigations [1-4].

In this process, the magnetic flux density of $0-0.1 \mathrm{~T}$ was used in the working gap of EDM process. Two solenoid coils were connected in series to generate the electromagnetic field. Winding copper wire of $0.13 \mathrm{~mm}$ diameter was surrounded around the core to form the solenoid. Soft iron with a high relative magnetic permeability was used for both the magnetic cores and the poles. The magnetic flux density in the working gap was varied by changing input current to the electromagnet and the magnetic field was kept orthogonal to the electric field. The workpiece and tool electrode were cleaned by acetone before and after each experiment and then dried in a dryer furnace.

The magnetic flux intensity was calculated as follows:

$$
H=N I / L,(\text { A.turn }) / m
$$

Where,

$\mathrm{H}$ : Magnetic flux intensity, (A. turn) / $\mathrm{m}$.

I: Current, A.

$\mathrm{N}$ : Number of turns.

$\mathrm{L}$ : Length of magnetic core, $\mathrm{m}$.

Also, the magnetic flux density was calculated as:

$$
\begin{gathered}
\beta=\mu \mathrm{H}, \text { (Tesla) } \\
\mu=\mu_{\mathrm{O}}{ }_{\mathrm{r}}
\end{gathered}
$$

where:

$\mu_{\mathrm{O}}=4 \pi \times 10^{-7}, \mu_{\mathrm{r}}=1$, for free space.

$\beta$ : Magnetic flux density, Tesla.

The value of current for two magnetic core with length $180 \mathrm{~mm}$ was equal to 1.08 amperes at a voltage equal to 220 volts and the number of turns for coiled copper wire around the magnetic core for test rig was 12000 turns. By applying equations 1 and 2, the values of magnetic flux intensity and magnetic flux density were calculated.

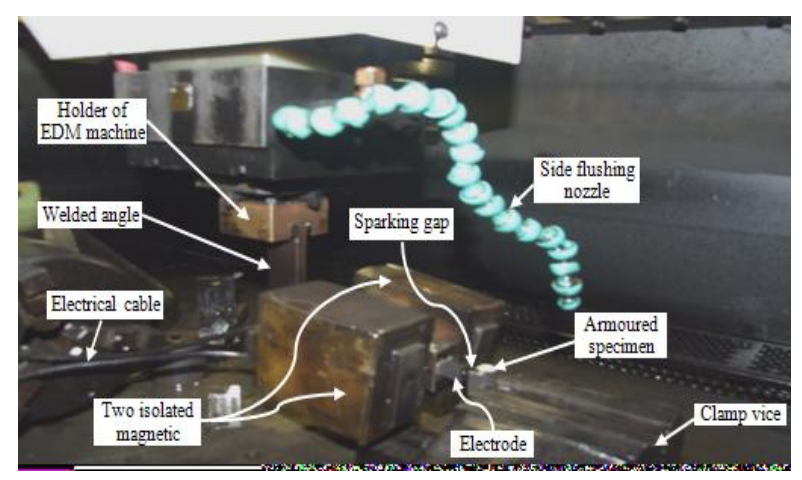

Fig. 1 Photograph of magnetic field test rig

Table 1, Chemical composition of armoured steel (wt \%)

\begin{tabular}{|c|c|c|c|c|c|c|c|}
\hline $\mathrm{C} \%$ & $\mathrm{Si} \%$ & $\mathrm{Mn} \%$ & $\mathrm{P} \%$ & $\mathrm{~S} \%$ & $\mathrm{Cr} \%$ & $\mathrm{Mo} \%$ & $\mathrm{Fe} \%$ \\
\hline 0.4381 & 0.251 & 0.912 & 0.0073 & $<0.0005$ & 0.4780 & 0.3883 & 96.27 \\
\hline $\mathrm{Ni} \%$ & $\mathrm{Al} \%$ & $\mathrm{Co} \%$ & $\mathrm{Cu} \%$ & $\mathrm{~V} \%$ & $\mathrm{~W} \%$ & $\mathrm{Sn} \%$ & \\
\hline 0.935 & 0.0482 & 0.0116 & 0.2220 & 0.0389 & $<0.0050$ & $<0.0010$ & \\
\hline
\end{tabular}




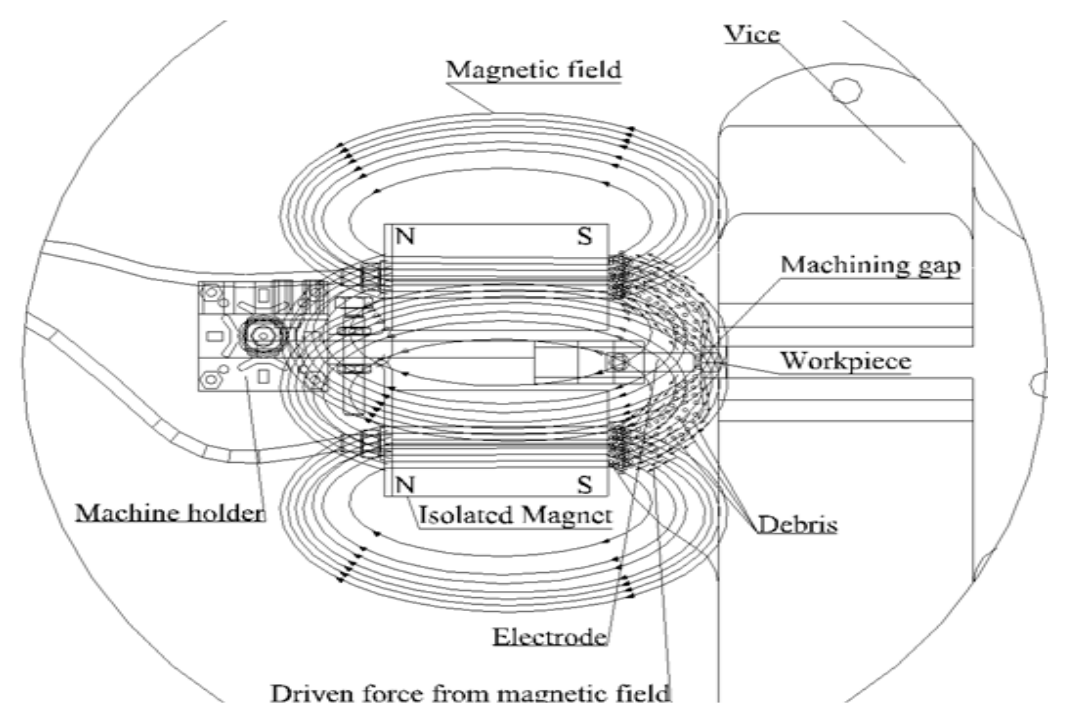

Fig. 2 Schematic diagram of the debris driven by the magnetic force in machining gap

The duty factor was calculated using the following formula:

$$
\text { Duty factor }(D)=\frac{\text { pulse on }- \text { time }}{(\text { pulse on }- \text { time })+(\text { pulse off }- \text { time })}
$$

The range of duty factor on an AGETRON advance (USA) die-sinking EDM machine was between 0.142 $\mu \mathrm{s}$ and $0.975 \mu \mathrm{s}$, the range of voltage for magnetic flux was between 0 volt, and 220 volts and the range of magnetic flux density was between 0 Tesla and 0.1 Tesla.

Table 2, EDM machining conditions

\begin{tabular}{|l|l|}
\hline Working condition & Value \\
\hline Workpiece material & Armoured steel \\
\hline Tool Polarity & Negative \\
\hline Electrode material & $\begin{array}{l}\text { Copper and } \\
\text { Graphite }\end{array}$ \\
\hline Peak Current, Ip & 20-60 A \\
\hline Magnetic flux density, $\beta$ & $0-0.1$ Tesla \\
\hline Duty factor, D & $0.142-0.975$ \\
\hline Dielectric fluid pressure, P & $0-1.2$ bar \\
\hline Dielectric fluid & Kerosene \\
\hline Dielectric flushing & Side flushing \\
\hline Depth of cut & $3 \mathrm{~mm}$ \\
\hline
\end{tabular}

The specimen and electrode were weighted before and after machining using a digital balance (Sartorius, type $1712,0.0001 \mathrm{~g}$ ). The metal removal rate was specified using the following equation:

$$
M R R=\left(W_{b}-W_{a}\right) / t
$$

Where,

$\mathrm{W}_{\mathrm{b}}$ : Specimen weight before machining $(\mathrm{g})$.

$\mathrm{W}_{\mathrm{a}}$ : Specimen weight after machining $(\mathrm{g})$.

$\mathrm{t}$ : Machining time (min).

The tool wear rate was specified using the following equation:

$$
\mathrm{TWR}=\left(\mathrm{T}_{\mathrm{b}}-\mathrm{T}_{\mathrm{a}}\right) / \mathrm{t}
$$

Where,

$\mathrm{T}_{\mathrm{b}}$ : Electrode weight before machining, $\mathrm{g}$.

$\mathrm{T}_{\mathrm{a}}$ : Electrode weight before machining, $\mathrm{g}$.

$\mathrm{t}$ : Machining time, min.

\subsection{Experimental Design and Modeling}

Response surface methodology (RSM) is an interaction of mathematical and statistical techniques for modelling and optimizing the response variable models involving quantitative independent variables [17-21]. coded and actual values of the input process parameters have been listed in Table 3. Experiments have been carried out according to the experimental plan based on central composite rotatable second order design (CCD) [19-21]. The Design of experiment matrix showing the actual values of the input process parameters is shown in Table 4. 
Through the use of the design of experiments and applying regression analysis, the modelling of the desired response to several independent variables can be gained [19]. If all variables are assumed to be measurable, the quadratic response surface model of $Y_{u}$ can be written as follows:

$$
Y_{u}=b_{o}+\sum_{i=1}^{k} b_{i} X_{i}+\sum_{j>i}^{k} b_{i j} X_{i} X_{j}+\sum_{i=1}^{k} b_{i i} X_{i}^{2} \pm \varepsilon(7)
$$

Where, $Y_{u}$ is the corresponding response function (or response surface), $X_{1}, X_{2}, X_{3} \ldots . . X_{\mathrm{k}}$ are coded values of the machining process parameters and $\varepsilon$ is the fitting error of the $u_{t h}$ observations. In this study, for four variables under consideration (Ip, $\beta, D$, and $P$ ), a second order polynomial regression model, called quadratic, model is proposed.

The coefficient $b_{\mathrm{o}}$ is the free term, the coefficients $b_{\mathrm{i}}$ are the linear terms, the coefficients $b i j$ are the interaction terms and the coefficients $b_{\mathrm{ii}}$ are the quadratic terms. Using the results presented in Figs. (38 ) the full form of the derived models can be presented.

Based on Eq. 6, the effect of input parameters (Table 4) on values of metal removal rate and tool wear rate has been evaluated by computing the values of various constants using Table 4 . The mathematical models of MRR and TWR when using copper and graphite electrodes can be expressed as follows:

$\mathrm{MRR}_{\mathrm{Cu}}=0.033+0.014 \mathrm{X}_{1}+2.25 \times 10^{-3} \mathrm{X}_{2}-9.8 \times 10^{-3} \mathrm{X}_{3}-$ $1.8 \times 10^{-3} \mathrm{X}_{4}-1.54 \times 10^{-3} \mathrm{X}_{1} \mathrm{X}_{3}+4.9 \times 10^{4} \mathrm{X}_{1} \mathrm{X}_{4}-4 \times 10^{-}$

${ }^{3} \mathrm{X}_{2} \mathrm{X}_{3}+1.63 \times 10^{-3} \mathrm{X}_{2} \mathrm{X}_{4}+2.9 \times 10^{-3} \mathrm{X}_{3} \mathrm{X}_{4}+1.83 \times 10^{-3} \mathrm{X}_{1}{ }^{2}$ -

$2.6 \times 10^{-4} \mathrm{X}_{2}^{2}-3.5 \times 10^{-3} \mathrm{X}_{3}^{2}+2.42 \times 10^{-4} \mathrm{X}_{4}^{2}$

$\mathrm{MRR}_{\mathrm{Gr}}=0.12-1.688 \times 10^{-3} \mathrm{X}_{1}-5.396 \times 10^{-3} \mathrm{X}_{2}+0.022 \mathrm{X}_{3^{-}}$ $1.963 \times 10^{-3} \mathrm{X}_{4}-0.010 \mathrm{X}_{1}{ }^{2}+4.010 \times 10^{-4} \mathrm{X}_{2}^{2}-0.017 \mathrm{X}_{3}{ }^{2}$ $5.361 \times 10^{-3} \mathrm{X}_{4}^{2}-3.294 \times 10^{-3} \mathrm{X}_{1} \mathrm{X}_{2}+8.819 \times 10^{-3} \mathrm{X}_{1} \mathrm{X}_{3}-$ $4.731 \times 10^{-3} \mathrm{X}_{1} \mathrm{X}_{4}+5.544 \times 10^{-3} \mathrm{X}_{2} \mathrm{X}_{3}-1.356 \times 10^{-3} \mathrm{X}_{2} \mathrm{X}_{4}$ $0.013 \mathrm{X}_{3} \mathrm{X}_{4}$
$\mathrm{TWR}_{\mathrm{cu}}=0.033+0.014 \mathrm{X}_{1}-6.6 \times 10^{-3} \mathrm{X}_{3}-3.583 \times 10^{4} \mathrm{X}_{4}^{-}$ $1.415 \times 10^{-3} \mathrm{X}_{1}^{2}-4.229 \times 10^{-4} \mathrm{X}_{2}^{2}-4.823 \times 10^{-3} \mathrm{X}_{3}^{2}-3.104 \times 10^{-}$ ${ }^{4} \mathrm{X}_{4}^{2}-2.238 \times 10^{-3} \mathrm{X}_{1} \mathrm{X}_{2}+9.5 \times 10^{-4} \mathrm{X}_{1} \mathrm{X}_{3}+2.425 \times 10^{-3} \mathrm{X}_{1} \mathrm{X}_{4}-$ $2 \times 10^{-3} \mathrm{X}_{2} \mathrm{X}_{3}+6.5 \times 10^{-4} \mathrm{X}_{2} \mathrm{X}_{4}+2.438 \times 10^{-3} \mathrm{X}_{3} \mathrm{X}_{4}$

$\mathrm{TWR}_{\mathrm{Gr}}=5.283 \times 10-3-2.750 \times 10-4 \mathrm{X} 1-2.417 \times 10-4 \mathrm{X} 2+$ $9.417 \times 10-4 X 3-7.5 \times 10-5 \times 4-3.854 \times 10-4 \times 12-1.042 \times 10-$ $5 \times 22-7.354 \times 10-4 \times 32-2.479 \times 10-4 X 42-1.5 \times 10-4 X 1 X 2$ $+2.5 \times 10-4 \mathrm{X} 1 \mathrm{X} 3-1.875 \times 10-4 \mathrm{X} 1 \mathrm{X} 4+2.250 \times 10-4 \mathrm{X} 2 \mathrm{X} 3-$ $3.750 \times 10-5 X 2 X 4-5.375 \times 10-4 X 3 X 4$

The adequacy of the provided models is checked using the analysis of variance (ANOVA). It can be noted that there are some terms omitted from the equations.

\section{RESULTS AND DISCUSSION}

\subsection{Effect of Machining Parameters Using Copper Electrode on MRR}

Metal removal rate in the EDM process assisted by magnetic field is a vital and significant factor due to its effect on the industrial economy. Based on the RSM model, Figs. (3-5) show the effect of the peak current on the MRR at various values of magnetic flux density, duty factor and dielectric fluid pressure. The non linear variation of the MRR with the peak current has been recorded. Generally, the MRR increases as the peak current increases and this may be explained in terms of heat and forces generated during the EDM process [18].

The increase of the discharge current means an increase in the discharge channel diameter and hence an increase in both of the crater diameter and depth which led to, an increase in MRR. As the peak current increases, both number and velocity of the charged ions in motion through the electrodes gap also increases [18].

Table 3, Coded and actual values of the input parameters

\begin{tabular}{|l|c|c|c|c|c|c|}
\hline \multirow{2}{*}{ Input parameters } & \multirow{2}{*}{ Symbol } & \multicolumn{5}{|c|}{ Levels } \\
\cline { 3 - 7 } & & -1 & -1 & 0 & +1 & +2 \\
\hline Peak current (Ip), A & $\mathrm{X} 1$ & 20 & 30 & 40 & 50 & 60 \\
\hline Magnetic flux density (ß),Tesla & $\mathrm{X} 2$ & 0 & 0.025 & 0.05 & 0.075 & 0.1 \\
\hline Duty factor (D) & $\mathrm{X} 3$ & 0.15 & 0.34 & 0.53 & 0.72 & 0.91 \\
\hline Dielectric fluid pressure (P), bar & $\mathrm{X} 4$ & 0.4 & 0.6 & 0.8 & 1 & 1.2 \\
\hline
\end{tabular}


Table 4, Experimental design matrix and results for copper and graphite electrodes

\begin{tabular}{|c|c|c|c|c|c|c|c|c|}
\hline \multirow{3}{*}{$\begin{array}{l}\text { Exp. } \\
\text { No. }\end{array}$} & \multicolumn{4}{|c|}{ Input parameters } & \multicolumn{4}{|c|}{ Experimental results } \\
\hline & \multirow[b]{2}{*}{$I p, A$} & \multirow[b]{2}{*}{$B$, Tesla } & \multirow[b]{2}{*}{$D$} & \multirow[b]{2}{*}{$P$, bar } & \multicolumn{2}{|c|}{ Copper electrode } & \multicolumn{2}{|c|}{ Graphite electrode } \\
\hline & & & & & $\begin{array}{l}\text { MRR, } \\
\mathrm{g} / \mathrm{min}\end{array}$ & $\begin{array}{l}\text { TWR, } \\
\text { g/min }\end{array}$ & $\begin{array}{l}\text { MRR, } \\
\text { g/min }\end{array}$ & $\begin{array}{l}\text { TWR, } \\
\text { g/min }\end{array}$ \\
\hline 1 & 30 & 0.025 & 0.34 & 0.6 & 0.031 & 0.028 & 0.0622 & 0.0028 \\
\hline 2 & 50 & 0.025 & 0.34 & 0.6 & 0.0532 & 0.0457 & 0.0567 & 0.0024 \\
\hline 3 & 30 & 0.075 & 0.34 & 0.6 & 0.0368 & 0.0331 & 0.048 & 0.002 \\
\hline 4 & 50 & 0.075 & 0.34 & 0.6 & 0.0682 & 0.0495 & 0.0394 & 0.0017 \\
\hline 5 & 30 & 0.025 & 0.72 & 0.6 & 0.0086 & 0.0073 & 0.1133 & 0.0052 \\
\hline 6 & 50 & 0.025 & 0.72 & 0.6 & 0.0329 & 0.0357 & 0.1346 & 0.0056 \\
\hline 7 & 30 & 0.075 & 0.72 & 0.6 & 0.0091 & 0.0083 & 0.1143 & 0.0053 \\
\hline 8 & 50 & 0.075 & 0.72 & 0.6 & 0.0267 & 0.0272 & 0.1396 & 0.0056 \\
\hline 9 & 30 & 0.025 & 0.34 & 1 & 0.0102 & 0.0105 & 0.093 & 0.004 \\
\hline 10 & 50 & 0.025 & 0.34 & 1 & 0.0432 & 0.0487 & 0.0881 & 0.0038 \\
\hline 11 & 30 & 0.075 & 0.34 & 1 & 0.0338 & 0.026 & 0.0944 & 0.0042 \\
\hline 12 & 50 & 0.075 & 0.34 & 1 & 0.0589 & 0.0469 & 0.0375 & 0.0016 \\
\hline 13 & 30 & 0.025 & 0.72 & 1 & 0.0077 & 0.0066 & 0.0952 & 0.0045 \\
\hline 14 & 50 & 0.025 & 0.72 & 1 & 0.0315 & 0.041 & 0.1053 & 0.0044 \\
\hline 15 & 30 & 0.075 & 0.72 & 1 & 0.0098 & 0.0095 & 0.097 & 0.0045 \\
\hline 16 & 50 & 0.075 & 0.72 & 1 & 0.0312 & 0.0362 & 0.1055 & 0.0044 \\
\hline 17 & 20 & 0.05 & 0.53 & 0.8 & 0.0084 & 0.0066 & 0.0861 & 0.0047 \\
\hline 18 & 60 & 0.05 & 0.53 & 0.8 & 0.073 & 0.0704 & 0.0712 & 0.0029 \\
\hline 19 & 40 & 0 & 0.53 & 0.8 & 0.0329 & 0.0336 & 0.1355 & 0.0059 \\
\hline 20 & 40 & 0.1 & 0.53 & 0.8 & 0.0318 & 0.0287 & 0.1071 & 0.0047 \\
\hline 21 & 40 & 0.05 & 0.15 & 0.8 & 0.034 & 0.024 & 0.013 & 0.001 \\
\hline 22 & 40 & 0.05 & 0.91 & 0.8 & 0.005 & 0.0031 & 0.0878 & 0.0038 \\
\hline 23 & 40 & 0.05 & 0.53 & 0.4 & 0.0349 & 0.0314 & 0.112 & 0.005 \\
\hline 24 & 40 & 0.05 & 0.53 & 1.2 & 0.0338 & 0.0318 & 0.0845 & 0.0037 \\
\hline 25 & 40 & 0.05 & 0.53 & 0.8 & 0.0347 & 0.032 & 0.1215 & 0.0053 \\
\hline 26 & 40 & 0.05 & 0.53 & 0.8 & 0.0335 & 0.0353 & 0.121 & 0.005 \\
\hline 27 & 40 & 0.05 & 0.53 & 0.8 & 0,0317 & 0.035 & 0.112 & 0.005 \\
\hline 28 & 40 & 0.05 & 0.53 & 0.8 & 0.0332 & 0.031 & 0.121 & 0.006 \\
\hline 29 & 40 & 0.05 & 0.53 & 0.8 & 0.0312 & 0.0284 & 0.1326 & 0.0053 \\
\hline 30 & 40 & 0.05 & 0.53 & 0.8 & 0.0323 & 0.0356 & 0.1175 & 0.0051 \\
\hline 31 & 40 & 0.05 & 0.53 & 0.8 & 0.0320 & 0.0332 & 0.1234 & 0.0052 \\
\hline
\end{tabular}

Those ions bomb the metal surface, causing stronger vibration to their particles. This, in turn, will lead to a high increase in temperature which accelerates the rate of melting and evaporization [22]. Further, the number and pressure of gas bubbles will increase, which explode with high ejecting forces when the discharge ceases causing removal of bigger volume of the crater molten metal. In addition, the greater ions number bombing the metal surface has a tearing effect. Therefore, the increase in discharge current means an increase in the rate of melting and hence in its rate of ejection. The increase in the discharge current that is applied to a same projected area means an increase in the discharge current intensity. Increase in current intensity higher than a certain limit, leads to arcing and to a decrease in the effective discharges number, with the resultant decrease in machining efficiency which subsequently leads to a decrease in MRR.

Figures (3-5) show the effect of magnetic flux density on MRR at various values of duty factor, dielectric fluid pressure and peak current. From these figures, it is clear that the linear nature of variation of the MRR with the magnetic flux density can be noticed. It can be seen from these figures that an increase in the magnetic flux density leads to a sharp increase in the MRR at different values of duty factor 
and dielectric fluid pressure expect at low level values of dielectric fluid pressure and high values of duty factor. This result can be attributed to the effective debris transportation achieved due to the presence of the magnetic field. In the absence of debris, fresh work material is continuously being exposed for sparking and hence greater MRR is achieved and electrode with negative polarity gives higher MRR [23].

Figure 4 shows the effect of the duty factor on the MRR at various values of peak current. It can be noted that the duty factor has a nonlinear effect on the MRR. In general, it is observed that the MRR decreases with the increase in the duty factor. This result is due to the high energy input (peak current and / or pulse - on time), with the resultant accumulation of debris in the gap. Hence, the material removal rate will decrease and material removal mechanisms caused by vaporization and melting were restricted [24].

Figure 5 shows the effect of dielectric fluid pressure on the MRR at various values of peak current. This figure indicates that the nature of variation of MRR at different dielectric fluid pressure follows nonlinear nature. Also, it has been observed that at suitable value of dielectric fluid pressure such as, 0.4 bar, the MRR is high, but at higher values of dielectric fluid pressure, the negative effect was occurred. This is due to; the increase of dielectric fluid pressure which increases the tendency for arcing and the decreases of the MRR. Thus, good flushing provides a good machining condition. Furthermore, it is found that the dielectric fluid pressure has a moderate effect on MRR. This result is in agreement with the results obtained previously [18].

\subsection{Effect of Machining Parameters on MRR Using Graphite Electrodes}

The influence of peak current on MRR is illustrated in Figures. (6-8) at different values of magnetic flux density, duty factor and dielectric fluid pressure. It can be seen that the material removal rate increases initially as peak current increases and then decreases. This result is attributed to the arcing phenomena [23]. The influence of the magnetic flux density on the MRR at various values of peak current can be evaluated from the Fig. 6.

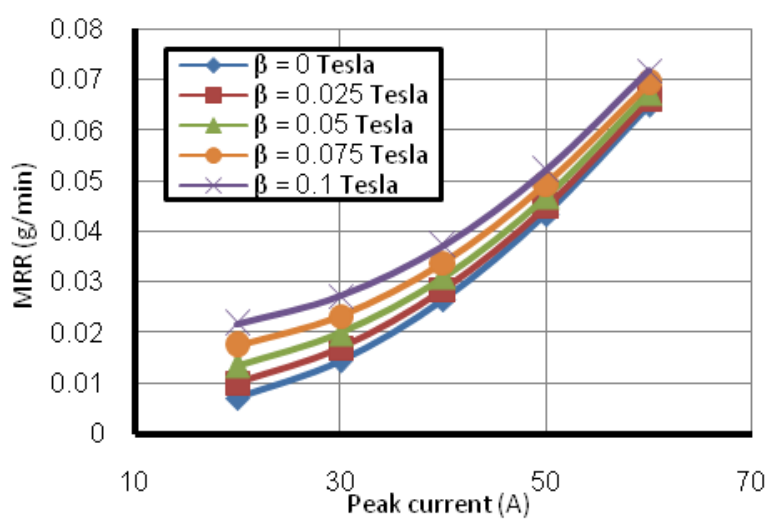

Fig. 3 Effect of peak current on MRR at various magnetic flux densities ( $D=0.53, P=0.8$ bar, copper elect.)

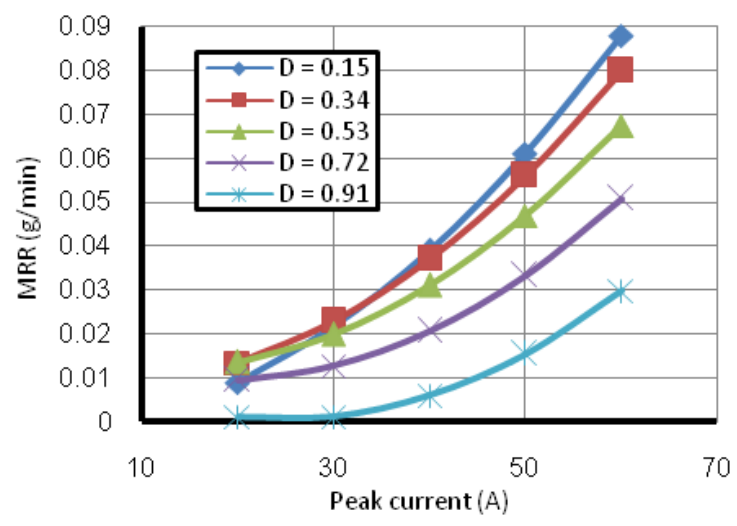

Fig. 4 Effect of the peak current on MRR at various duty factors ( $\beta=0.05$ Tesla, $P=0.8$ bar, copper elect.)

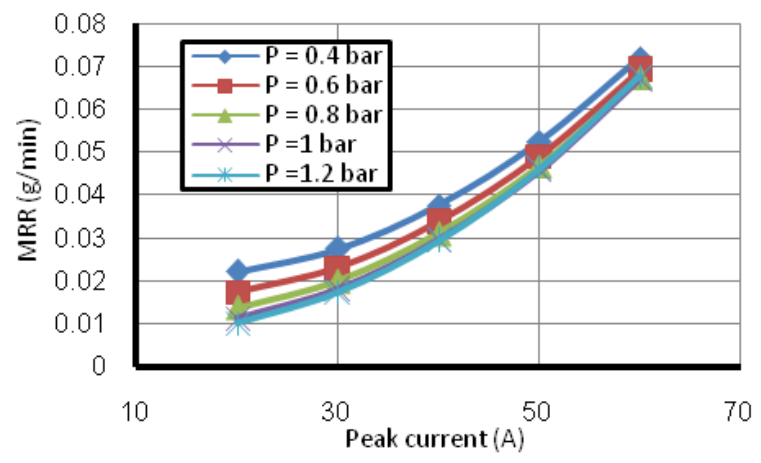

Fig. 5 Effect of the peak current on MRR at various dielectric fluid pressure, $\mathrm{s}(\beta=0.05$ Tesla, $D=0.53$, copper elect.)

It is observed that an increase in the magnetic flux density causes a decrease in the MRR in a linear nature. This result is due to the high energy input (peak current and / or pulse - on time), with the resultant accumulation of debris in the gap. The debris particles can then form an electrically conducting path between 
the electrode and workpiece, causing unwanted discharge which converts to arcs, with consequential damage to both the electrode and the workpiece. Hence the material removal rate will decrease as shown in Figures (6-8). The magnetic flux density has a negative effect on the MRR when machining the workpieces by graphite electrode [23].

Figure 7 exhibits the influence of the duty factor on the MRR at various values of peak current. The relationship between the MRR and duty factor is nonlinear. The figures show that the MRR increases initially as duty factor increases and then decreases. This result is attributed to the arcing phenomena as will be illustrated later.

The influence of dielectric fluid pressure on MRR is demonstrated in Fig.8 at different values of peak current. It can be seen that the material removal rate changed significantly with the change in the dielectric fluid pressure, even though there is a gradual decreasing trend. One of the most important factors in successful EDM work is the flushing, which is metal particles generated in the spark gap. It involves the distribution of dielectric flow through the spark gap to remove gaseous and solid debris generated during EDM and to maintain the dielectric temperature well below its flash point. Uneven and significant electrode wear, which affects accuracy and surface roughness, are the usual consequence of improper flushing. Improper flushing can also reduce removal rates due to unstable machining conditions and arcing around regions with high concentration of debris.

Good flushing provides good machining conditions. The use of flushing in maintaining a state of deionization in the gap at the end of long pulse duration is well recognized. When the flushing pressure is too low, the flushing cannot remove the gaseous and solid debris after each discharge. However, if the dielectric pressure is too high, no proper machining can be done as the ionized channel is continuously wash away and the relative wear ratio will increase. The MRR is slightly decreased with higher flushing pressure. Excessive flushing pressure can also accelerate electrode wear and create turbulence in the cavity [22].

\subsection{Effect of Machining Parameters on TWR Using Copper Electrodes}

Figures (9-11) depict the relationship between peak current and TWR in the magnetic force-assisted EDM under various values of magnetic flux density, duty factor and dielectric fluid pressure. The TWR was found to increase with the increase of peak current. It is interesting to note that these figures show a trend opposite to that displayed by graphite in Figures (1214). This abnormality of the shape of the graphs (9-11) of copper electrode could be due to the electrode polarity used in this experiment. Copper is normally used as positive electrode polarity, but in this experiment it is used as negative polarity for standardization and comparison purpose. Better machining performance is obtained generally with the electrode as a cathode and the workpiece as the anode. Tools with negative polarity give higher material removal rate, lower tool wear and better surface finish [ 22-25].

The results showed that the machining armoured steel; with negative electrode polarity is more desirable. This is because the material removal rate is higher when using copper electrode as shown in Figures (9-11). Further, the TWR is lower when using graphite electrode as shown in Figs. (12-14) than using a positive electrode. In the present experimental results, the negative polarity was used. The material removal rate was dependent on anode potential drop. When the current was high enough, there was evaporation of the metal from the anode. This stream of atoms coming out from the anode interfered with the electrons coming to the anode. Some of the metal atoms were ionized, but the electrons gained the additional energy of the anode drop and slammed into the anode, causing more vaporization and material removal. This anode received the electrons, which give up their work function energy (heat of vaporization of the electrons) and their energy due to the anode drop [22].

The graphite electrode was vaporized from the anode or thrown off in droplets when the temperature was above the melting point $\left(3350^{\circ} \mathrm{C}\right)$ of the anode and this agrees with the results obtained by $[22,25]$. These effects yielded a high machining rate and very low tool wear as shown in Figs. (12-14). However, as illustrated later, the MRR in case of used graphite electrodes is decreased which is due to the arcing phenomena for the graphite electrodes. The increase of magnetic flux density leads to the reduction of TWR as shown in Fig. 9. This result is due to the improvement of the flushing condition and the stability of the process. At low levels of duty factor, it has been noticed that TWR increased, which consequently implies the presence of arcing. Obviously, these conditions may lead to vigorous sparking on the electrode surface and the propagation of tool wear $[15,23]$. 


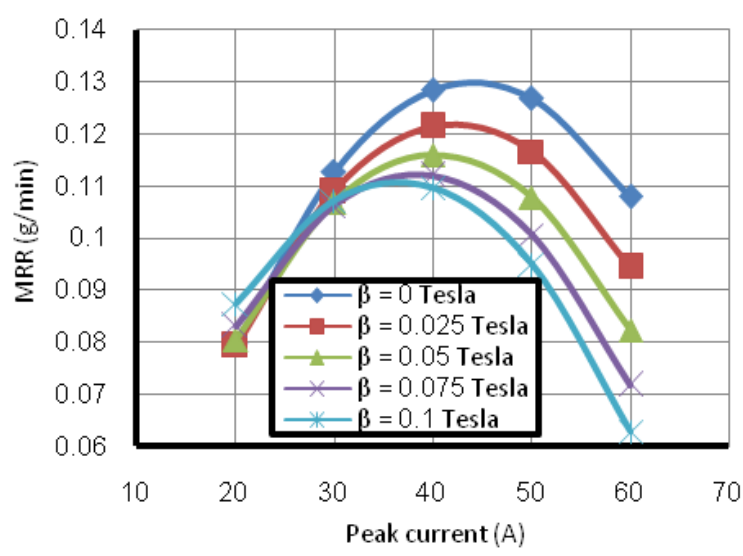

Fig. 6 Effect of the peak current on MRR at various magnetic flux densities $(D=0.53, P=0.8$ bar, graphite elect.)

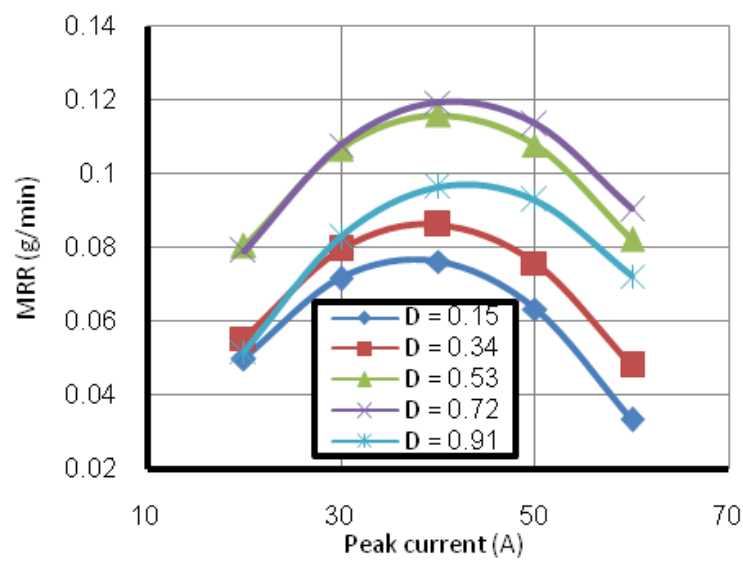

Fig. 7 Effect of the peak current on MRR at various duty factors $(\beta=0.05$ Tesla, $P=0.8$ bar, graphite elect.)

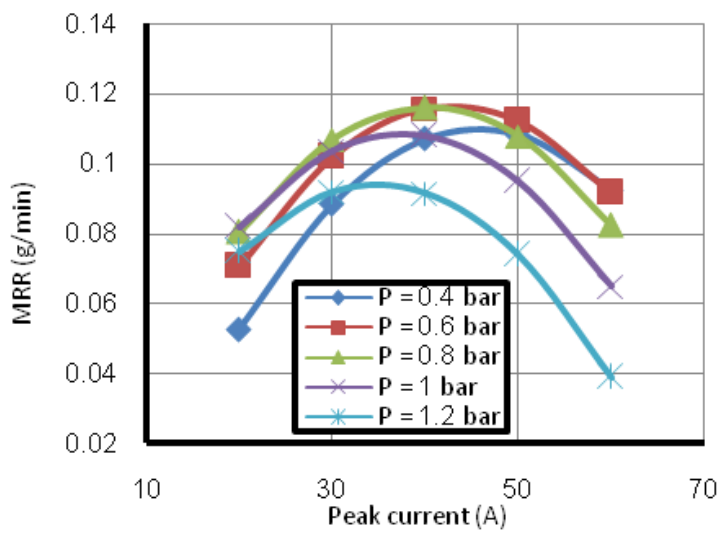

Fig. 8 Effect of the peak current on MRR at various dielectric fluid pressure, $s(\beta=0.05$ Tesla, $D=0.53$, graphite elect.)

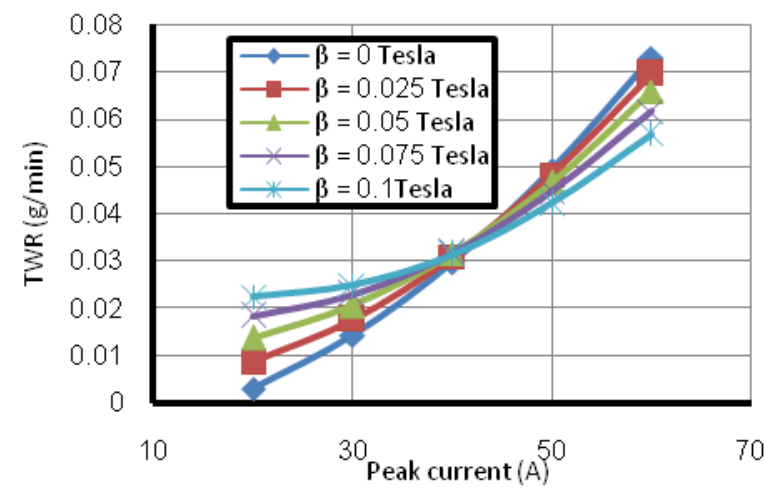

Fig. 9 Effect of the peak current on TWR at various magnetic flux densities $(D=0.53, P=0.8$ bar, copper elect.)

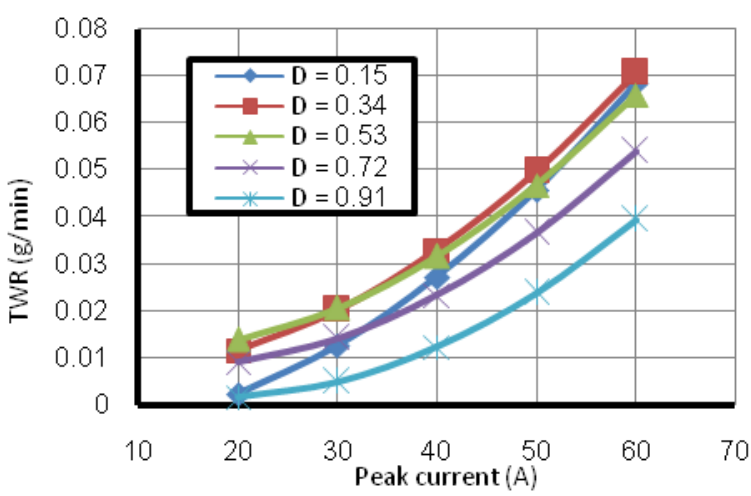

Fig. 10 Effect of the peak current on TWR at various duty factors $(\beta=0.05$ Tesla, $P=0.8$ bar, copper elect.)

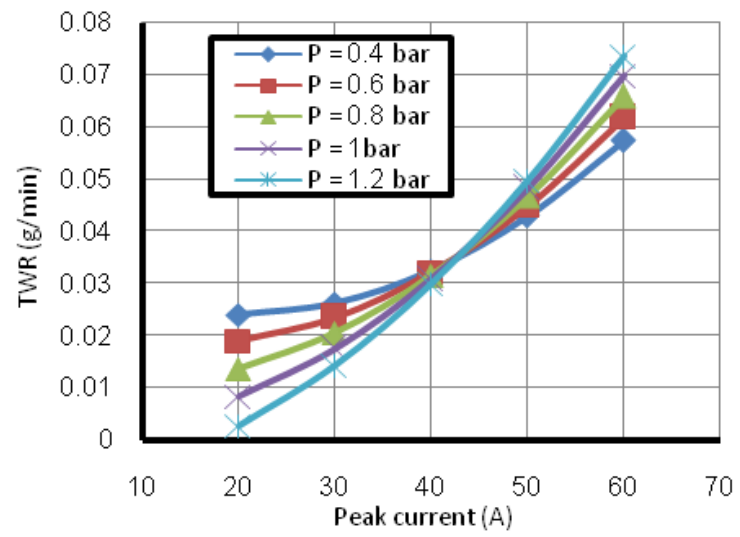

Fig. 11 Effect of the peak aurrent on TWR at various dielectric fluid pressure, $\mathrm{s}(\beta=0.05$ Tesla, $D=0.53$, copper elect.)

Figure (10) shows the relationship between duty factor and TWR when magnetic force assisted EDM under various values of peak current. As the experimental results revealed that, the electrode wear rate was reduced upon increasing the duty factor. The discharge column would expand to reduce the energy density of 
discharge spot at upon increasing the duty factor. In general, the effect of material removal mechanisms caused by melting, vaporization, as well as impulsive force of exploding dielectric fluid was decreased. Therefore, TWR was decreased at longer pulse duration and high values of duty factor. This can be attributed to the fact that duration at larger peak current would lead to the generation of massive amount of pyrolytic carbon from kerosene dielectric. The pyrolytic carbon could deposit on the electrode surface which form a protective layer, resulting in the decrease of TWR $[22,23]$.

The effect of dielectric fluid pressure on the TWR, while keeping the other parameters at center level, is shown in Fig. 11. The nonlinear nature of variation of TWR with the dielectric fluid pressure has been observed. The figure reflects that the dielectric fluid pressure has a moderate effect on TWR. The increase in the dielectric fluid pressure reduces TWR. Thus, an adequate flushing in the gap zone is really important for the stability of the EDM process. Of course, excessively high values for the flushing pressure are expected to create turbulence in the dielectric and, as a consequence of that a worsening in the TWR and this is agree with the results obtained by [18].

\subsection{Effect of Machining Parameters on TWR Using Graphite Electrodes}

The effect of peak current on TWR is depicted in Figs. (12-14). As shown in these figures, an increase in peak current leads to a decrease in TWR. This is due to the presence of magnetic flux field and the increasing of dielectric fluid pressure.

The effect of magnetic flux density on TWR is demonstrated in Fig. 12 at various values of peak current. It is observed that the TWR decreases with the increase of the magnetic flux density. This is due to the stability of the process and the improvement of the flushing pressure. The stability of the process may be attributed to the magnetic flux field. The surplus workpiece materials were removed from the machining area through melting, vaporization and dielectric explosion forming machining debris. Extra discharge energy was delivered to the machining zone; the more the debris was produced within the dielectric fluid. The extensive debris accumulated in the machining gap would interrupt the progress of EDM, and the stability of EDM would be deteriorated. When an assisted device of magnetic force was cited to the EDM cutting zone, the debris would be driven by the magnetic force quickly, and the probability of abnormal discharge would be diminished. Therefore, the TWR of the EDM was not facilitated by assisting magnetic force [23].

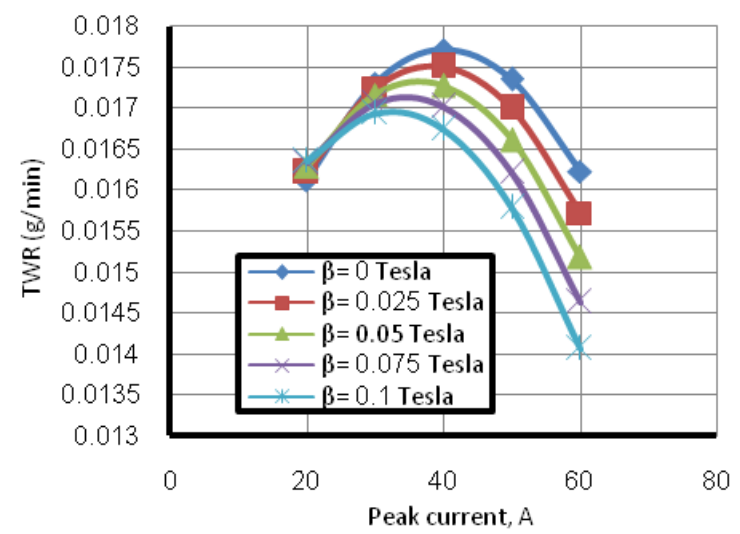

Fig. 12 Effect of the peak current on TWR at various magnetic flux densities ( $D=0.53, P=0.8 \mathrm{bar}$, graphite elect.)

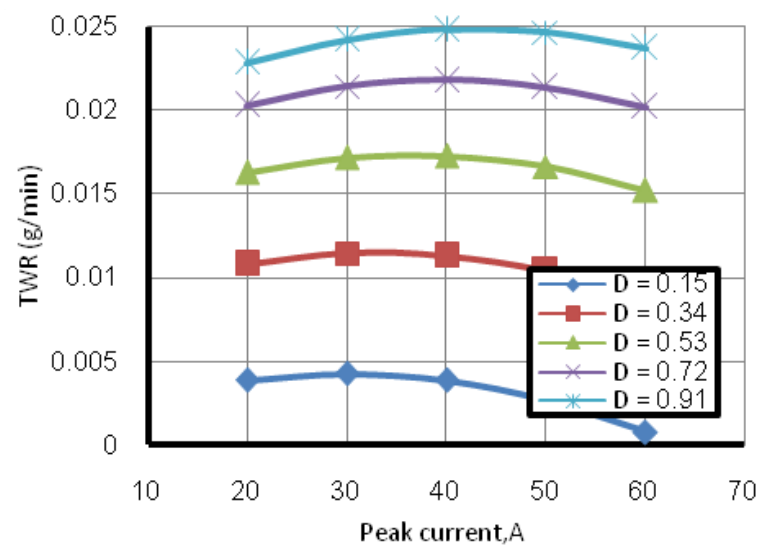

Fig. 13 Effect of the peak current on TWR at various duty factors (hold values: $\beta=0.53$ Tesla, $P=0.8$ bar, graphite elect.)

Figure 13 shows the effect of duty factor on the TWR at various values of peak current. The figure shows a non linear relationship between TWR and duty factor. It is noted that the TWR increases with the increase of the duty factor. This result may be attributed to the arcing phenomena as will be illustrated later. The probability of abnormal discharge would be not diminished with the improvement of the duty factor and pulse duration will increase TWR for graphite electrodes. 


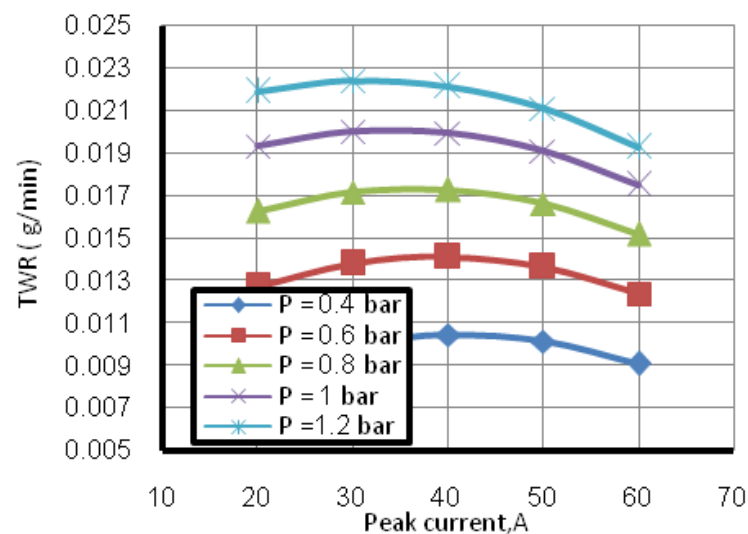

Fig. 14 Effect of the peak current on TWR at various dielectric fluid pressure,s $(\beta=0.05$ Tesla, $D=0.53$, graphite elect. )

Figure 14 shows the effect of dielectric fluid pressure on the TWR at various values of peak current. The non linear nature of variation of TWR with the dielectric fluid pressure has been observed. The figure reflects that the flushing pressure has a moderate effect on TWR. The increase in the flushing pressure decreases TWR. Thus, an adequate flushing in the gap zone is really important for the stability of the EDM process [18].

\subsection{Comparative Study}

Figure. 15 shows a comparison between MRR obtained by EDM assisted by magnetic field and conventional EDM using copper and graphite electrodes. As shown in this figure, the MRR obtained by EDM assisted by magnetic field was higher than that by conventional EDM when using copper electrode and the opposite effect was occurred when using graphite electrode. This result can be attributed to the effective debris transportation due to the presence of the magnetic field. In the absence of debris, fresh work material is continuously being exposed to sparking and hence greater MRR is achieved. Furthermore, copper electrode with negative polarity gives higher MRR. Therefore, the high energy input (peak current and / or pulse - on time), results in an accumulation of debris in the gap. The debris particles can then form an electrically conducting path between the graphite electrode and workpiece, causing unwanted discharge which converts to arcs, with consequential damage to both the graphite electrode and the workpiece. Hence the material removal rate will decrease as shown in Fig. 16. The magnetic flux density has a negative effect on the MRR when machining the workpieces by graphite electrode.
Figure 16 shows a comparison of TWR obtained by EDM assisted by magnetic field and conventional EDM using copper and graphite electrodes. As shown in this figure, the presence of magnetic field reduces the TWR. This result is due to the improvement of the flushing condition and the stability of the process. So assisting EDM with magnetic field is a fruitful and beneficial process that leads to an increase in metal removal rate and tool wear rate significantly, as compared to that achieved with the conventional EDM of some $33 \%$ and $2 \%$, respectively when using copper electrodes. Furthermore, a decrease in both metal removal rate and tool wear rate significantly, as compared to that achieved with the conventional EDM of some $16.3 \%$ and $16.8 \%$, respectively when using graphite electrodes.

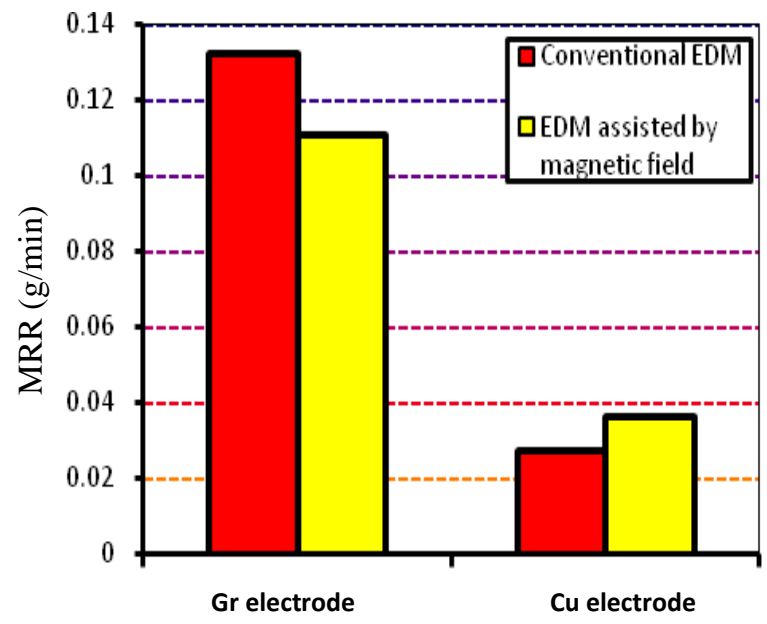

Fig. 15 Comparison of MRR obtained by EDM ssisted by magnetic field and conventional EDM at various magnetic flux densities (hold values: $\mathrm{Ip}=40 \mathrm{~A}, \mathrm{D}=0.53$, $\mathrm{P}=0.8$ bar)

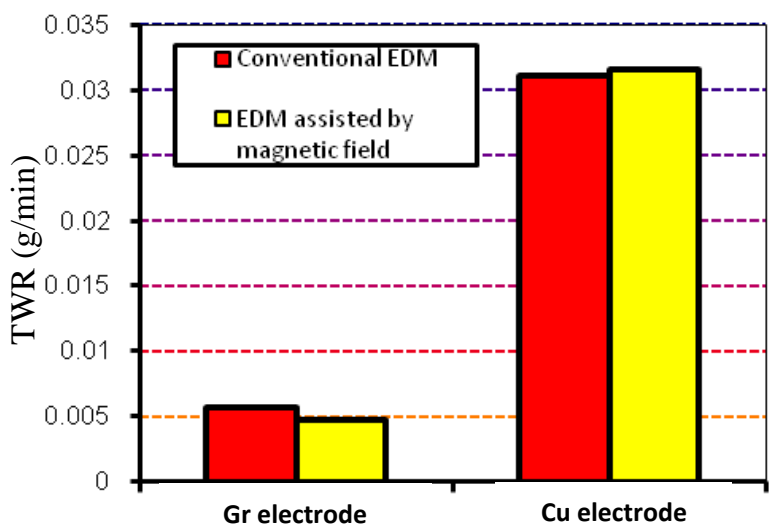

Fig. 16 Comparison of TWR obtained by EDM assisted by magnetic field and conventional EDM at various magnetic flux densities (hold values: $\mathrm{I}=40 \mathrm{~A}$, $\mathrm{D}=0.53, \mathrm{P}=0.8$ bar $)$ 


\section{CONCLUSIONS}

1. The metal removal rate increases with the increase of the magnetic flux density and peak current value. The effect of duty factor was limited. The dielectric fluid pressure has a moderate effect during machining of EDM assisted by magnetic field with copper electrodes. In case of using graphite electrodes the metal removal rate increases with the increase of the peak current value and duty factor initially and then decreases. The effect of magnetic flux density was limited and also the dielectric fluid pressure has a moderate effect during the machining of EDM assisted by magnetic field.

2. Lower tool wear rate has been obtained at the parametric combination of higher magnetic flux density and higher duty factor. It has also been found that the increase of peak current increases tool wear, while the dielectric fluid pressure has a moderate effect when machining by EDM assisted by magnetic field with copper electrodes.

3. Assisting EDM with magnetic field is a fruitful and beneficial process that leads to an increase in metal removal rate and tool wear rate significantly, as compared to that achieved with the conventional EDM of some $33 \%$ and $2 \%$, respectively when using copper electrodes. Furthermore, a decrease in both metal removal rate and tool wear rate significantly, as compared to that achieved with the conventional EDM of some $16.3 \%$ and $16.8 \%$, respectively when using graphite electrodes.

\section{ACKNOWLEDGMENTS}

The authors acknowledge the assistance provided by Eng. Nabil. H. Anwer, chairman of Kader Factory for Developed Industries, Arab Organization for Industrialization (AOI), Cairo, Egypt, for his help in the preparing the materials and carrying out the experiments on the EDM cavity sinking machine.

\section{REFERENCES}

[1] O.A. Abuzeid, "On the effect of electrodischarge machining parameters on the fatigue life of AISI D6 tool steel”, J. Mater. Process. Technol., Vol.68, (1997) pp.27-32.

[2] W. Szhao, Q.G. Meng and Z.L. Wang, "The Application of research on powder mixed EDM in rough machining", J.Mater. Process.Technol., Vol.129, (2002), pp.30-33.

[3] H.E. De Bruijn, T.H. Delft and A.J. Pekelharig, "Effect of a magnetic field on the gap cleaning in
EDM", Annals of the CIRP, Vol.27, (1978), pp.93-95.

[4] K.P. Rajurkar and S.M. Pandit, "Formation and ejection of EDM debris", Transactions of the ASME108, Vol.2, (1988), pp.22-26.

[5] T. Masuzawa, X. Cui and N. Taniguchi, "Improved jet flushing for EDM", Annals of the CIRP41, (1992), pp.239-242

[6] J.S. Soni, "Microanalysis of debris formed during rotary EDM of titanium alloy (Ti6Al4V) and die steel (T215Cr12)", Wear, Vol.177, (1994), pp.7179.

[7] Y.F. Lou, "The dependence of inter space discharge transitivity upon the gap debris in precision electro discharge machining", J. Mater. Process. Technol., Vol. 68, (1997), pp.121-131.

[8] S. Cetin, A. Okada and Y. uno, "Effect of debris accumulation on machining speed in EDM", International J. of. Elec. Machining., Vol. 9, (2004), pp.9-14.

[9] D. Kremer, C. Lhiaubet and A. Moisan, "A study of the effect of synchronizing ultrasonic vibrations with pulse in EDM", Annals of the CIRP, Vol.40, (1991), pp.211-214.

[10] T.B. Thoe, D.K. Aspinwall and N. killey, "Combined ultrasonic and electrical discharge machining of ceramic-coated nickel alloy", J. Mater. Process. Technol., Vol.92-93, (1999), pp.323-328.

[11] Y.C. Lin, B.H. Yan and Y.S. chang, "Machining characteristics of titanium alloy (Ti-6Al-4V) using combination process of EDM with USM", J. Mater. Process. Technol., Vol.104, (2000),pp. 171-177.

[12] Q.H. Zhang, J.H. Zhang, J.X. Deng, Y. Qin and Z.W. Niu, "Ultrasonic vibration electrical discharge machining in gas", J. Mater. Process. Technol., Vol.129, (2002), pp.135-138.

[13] Y.C. Lin, B.H. Yan and F.Y. Huang, "Surface modification of $\mathrm{Al}-\mathrm{Zn}-\mathrm{Mg}$ aluminum alloy using combined process of EDM with USM", J. Mater. Process. Technol., Vol.115, (2001), pp.359-366.

[14] R. Snoeys, F. Staelens and W. Dekeyser. "Current trends in non-conventional material removal processes", Annals of CIRP, Vol.35/2 (1986), pp. 467-480.

[15] G. Derringer and R. Suich, "Simultaneous optimization of several response variables", J. of Quality. Techan., Vol.12, (1980), pp. 214-219.

[16] E.D. Castillo, D.C. Montgomery and D.R McCarville, "Modified desirability functions for multiple response optimization", J. of. Quality Technl., Vol. 28, (1996), pp. 337-345. 
[17] M.S. Hewidy, T.A. El-Taweel, and M.F. El-Safty "Modeling the machining parameters of wire electrical discharge machining of Inconel 601 using RSM", J. Mater. Process. Technol., Vol.169, (2005), pp. 328-336.

[18] T. El-Taweel, "Multi-response optimization of EDM with $\mathrm{Al}-\mathrm{Cu}-\mathrm{Si}-\mathrm{TiC} \quad \mathrm{P} / \mathrm{M}$ composite electrode", Int. J. Adv. Manuf. Technol., Vol.44 (2009), pp. 100-113.

[19] D.C. Montgomery, "Design and analysis of experiments", Wiley, New York, (2001).

[20] J. Antony, "Design of experiments for engineers and scientists", Linacre House, Jordan Hill, Oxford OX2 8DP, (2003).

[21] A.B. Puri, B. Bhattacharyya, "Modeling and analysis of white layer depth in a wire-cut EDM process through response surface methodology",
Int. J. Adv. Manuf. Technol., Vol.25 (2005), pp. 301-307.

[22] A. fayed, "Machining of die materials by electric discharge machining (EDM)", M.Sc. thesis, Shebin El Kom, Faculty of Engineering, Mounifia University, 1990, Egypt.

[23] Y. Lin and Ho. Lee, "Machining characteristics of magnetic force-assisted EDM", Int. J. Mach. Tools. Manuf., Vol.48, (2008), pp.1179 - 1186.

[24] H.C. Tsai, B.H. Yan and F.Y. Huang, "EDM performance of $\mathrm{Cr} / \mathrm{C}$ - based composite electrodes", Int. J. Mach. Tools. Manuf., Vol.43, (2003), pp.245- 252.

[25] Y.Lin and Ho. Lee, "Optimization of machining parameters using magnetic force assisted EDM based on Taguchi method", J. Mater. Process. Technol., Manuscript Draft Number: PROTEC-D08-00400. 